\title{
Características florais e polinizadores na qualidade de frutos de cultivares de maracujazeiro-azedo
}

\author{
Simone Santos de Oliveira Cobra( ${ }^{(1)}$, Celice Alexandre Silva(1), Willian Krause(1), Daianny Correia Dias ${ }^{(2)}$, \\ Isane Vera Karsburg(1) e Anderson Fernandes de Miranda ${ }^{(2)}$
}

\begin{abstract}
(1)Universidade do Estado de Mato Grosso (Unemat), Programa de Pós-Graduação em Genética e Melhoramento de Plantas, Rodovia MT-358, Km 07, Jardim Aeroporto, CEP 78300-000 Tangará da Serra, MT, Brasil. E-mail: siimone_@msn.com, celice@unemat.br, krause@unemat.br, isane9@yahoo.com.br (2)Unemat, Departamento de Ciências Biológicas, Rodovia MT-358, Km 07, Jardim Aeroporto, CEP 78300-000 Tangará da Serra, MT, Brasil. E-mail: daiannycdias@gmail.com, anderson@unemat.br
\end{abstract}

Resumo-O objetivo deste trabalho foi determinar as características florais de oito cultivares de maracujazeiro-azedo e identificar seus polinizadores, bem como avaliar a influência da polinização natural na qualidade dos frutos, na região de Tangará da Serra, MT. Utilizou-se o delineamento inteiramente casualizado, com dez repetições e uma flor por parcela para avaliar a morfometria, e com quatro repetições e cinco flores por cultivar para determinar o índice de frutificação. Avaliaram-se os seguintes parâmetros: morfologia e morfometria floral, longevidade floral, frequência de visitantes florais, índice de frutificação natural e qualidade de fruto. A morfologia e a morfometria das flores foram compatíveis com a polinização por abelhas de grande porte; também foram compatíveis com a polinização por abelhas de médio porte nas cultivares IAC-275-Maravilha, IAC-277-Jóia, BRS SC1, BRS RC e BRS GA1. A maior longevidade floral foi observada nas cultivares IAC-277-Jóia, BRS GA1, BRS RC e BRS OV1. A frequência de abelhas como Xylocopa (2,0\%) e Bombus (3,9\%) foi baixa, e 'BRS GA1' recebeu o maior número de visitas destas abelhas. O índice de frutificação natural foi baixo $(36,67 \%)$. Os frutos de polinização natural apresentam características físicas compatíveis com as exigidas pelo mercado consumidor.

Termos para indexação: Passiflora edulis, abelhas silvestres, longevidade, morfometria, polinização natural.

\section{Floral traits and pollinators on fruit quality of sour passion fruit cultivars}

\begin{abstract}
The objective of this work was to determine the floral traits of eight cultivars of sour passion fruit and identify their pollinators, as well as to evaluate the influence of natural pollination on fruit quality, in the region of Tangará da Serra, MT, Brazil. A completely randomized experimental design was carried out, with ten replicates and one flower per plot to evaluate morphometry, and with four replicates and five flowers per cultivar to determine the fruiting rate. The following parameters were evaluated: flower morphology and morphometry, flower longevity, frequency of floral visitors, natural fruiting rate, and fruit quality. Flower morphology and morphometry were compatible with pollination by large-size bees; they were also compatible with pollination by medium-size bees for the cultivars IAC-275-Maravilha, IAC-277-Jóia, BRS SC1, BRS RC, and BRS GA1. The greatest flower longevity was observed for the IAC-277-Jóia, BRS GA1, BRS RC, and BRS OV1 cultivars. The frequency of bees as Xylocopa (2.0\%) and Bombus (3.9\%) was low, and 'BRS GA1' received the highest number of these bee visits. Natural fruiting rate was low $(36.67 \%)$. Naturally pollinated fruit show physical traits compatible with those required by the market standards.
\end{abstract}

Index terms: Passiflora edulis, wild bees, longevity, morphometry, natural pollination.

\section{Introdução}

A família Passifloraceae compreende cerca de 600 espécies, e o Brasil é um dos países com maior diversidade delas. O gênero Passiflora é o mais representativo, com 135 espécies (Bernacci et al., 2013). Considerada uma planta de "dias longos", pois necessita entre 11 e 12 horas de luz para florescer, o maracujazeiro-azedo (Passiflora edulis Sims) é a principal espécie comercializada. A antese inicia-se em torno das 12:00 h, momento em que os estiletes encontram-se em posição vertical e curvam-se gradualmente, até que o estigma atinja o mesmo nível das anteras (Ruggiero, 1973).

A longevidade floral pode influenciar o número de visitas do polinizador, a quantidade e a qualidade do

Pesq. agropec. bras., Brasília, v.50, n.1, p.54-62, jan. 2015

DOI: 10.1590/S0100-204X2015000100006 
pólen recebido e disseminado (Harder \& Johnson, 2005) e, também, possibilitar maior produção de frutos. Flores com antese precoce e senescência mais tardia ampliam o tempo de trabalho do produtor para a realização da polinização manual e, também, tornam a flor disponível aos polinizadores naturais por um período maior. Por ser uma planta alógama, depende da polinização cruzada para a produção de frutos. Caso não haja polinização, as flores abertas murcham e caem. Se houver polinização e fecundação, a flor fecha o perianto e tem início o desenvolvimento do fruto (Bruckner \& Silva, 2001).

A polinização cruzada pode ser realizada de forma artificial ou natural. Nos picos de floração, a polinização manual implica custos de mão de obra que podem atingir $15 \%$ do total dos custos de produção (Vieira et al., 2010). A polinização manual é indicada em plantios localizados em áreas infestadas com pragas, em que o uso frequente de inseticidas é inevitável e, principalmente, em áreas em que os polinizadores naturais são escassos (Junqueira et al., 2001). A carência de polinizadores, em áreas de cultivos comerciais, acarreta problemas como baixa produtividade, falta de padronização dos frutos quanto ao aspecto, sabor, coloração, uniformidade de tamanho e formato (Brasil, 2000).

A compreensão sobre o modo de adaptação das características reprodutivas de diferentes cultivares comerciais de maracujá às condições edafoclimáticas pode auxiliar na condução e manejo da cultura (Cruz \& Campos, 2009) em uma dada região.

Nenhuma das cultivares de maracujazeiro-azedo lançadas no mercado foi desenvolvida para o Estado de Mato Grosso. Porém, 'BRS SC1', 'BRS OV1', 'BRS GA1', 'FB 200 Yellow Master', 'IAC-275-Maravilha' e 'IAC-277-Jóia' têm sido plantadas (Krause et al., 2012a). A 'BRS RC' e a 'FB 300 Araguari' foram lançadas recentemente pelos programas de melhoramento da Embrapa Cerrados e Flora Brasil, respectivamente. Assim, é importante avaliar a biologia reprodutiva destas cultivares, nas condições edafoclimáticas do Estado de Mato Grosso.

O objetivo deste trabalho foi determinar as características florais de oito cultivares de maracujazeiro-azedo e identificar seus polinizadores, bem como avaliar a influência da polinização natural na qualidade dos frutos dessas cultivares, na região de Tangará da Serra, MT.

\section{Material e Métodos}

Os experimentos foram realizados em 2013, no campus de Tangará da Serra, da Universidade do Estado de Mato Grosso (Unemat), a $14^{\circ} 30^{\prime} \mathrm{S}, 57^{\circ} 25^{\prime} \mathrm{W}$, à altitude de $321,5 \mathrm{~m}$. $\mathrm{O}$ clima da região, conforme classificação de Köppen \& Geiger (1928), é do tipo Aw, tropical úmido megatérmico, com duas estações bem definidas - uma chuvosa, de outubro a março, e uma estação seca de abril a setembro. A precipitação média anual varia de 1.300 a $2.000 \mathrm{~mm}$, com temperaturas de 16 a $36^{\circ} \mathrm{C}$ (Martins et al., 2010).

Os experimentos foram implantados em janeiro de 2013, com oito cultivares de maracujazeiro-azedo (BRS SC1, BRS GA1, BRS OV1, BRS RC, FB 200 Yellow Master, FB 300 Araguari, IAC-275-Maravilha e IAC-277-Jóia) da coleção ativa de germoplasma da Unemat, tendo-se utilizado cinco plantas de cada cultivar para as avaliações. Os experimentos foram realizados durante a estação seca, entre os meses de maio e setembro.

Durante o período experimental, a necessidade hídrica das plantas foi complementada com irrigação por sistema de gotejamento, tendo-se aplicado a água de forma suplementar, nos períodos de estiagem. O sistema de condução foi o de espaldeira vertical, com um fio de arame liso número 12, a $2 \mathrm{~m}$ de altura do solo, com distância de $6 \mathrm{~m}$ entre as estacas. O espaçamento de plantio foi de $3 \mathrm{~m}$ entre plantas e $3,5 \mathrm{~m}$ entre as linhas.

As caracterizações morfológica e morfométrica das flores foram realizadas de acordo com os descritores para Passiflora (Brasil, 2008), com adaptações. Para o estudo da morfologia floral, coletaram-se dez flores por cultivar, tendo-se realizado a descrição de acordo com as seguintes características: número e coloração das sépalas e pétalas; número das séries de corona; forma e coloração do androginóforo; presença de opérculo; forma do ovário; número e forma dos estames e estigma. Para a análise da morfometria floral, utilizouse um delineamento inteiramente casualizado, com dez repetições e uma flor por parcela.

Avaliaram-se, com auxílio de um paquímetro digital, as seguintes variáveis: comprimento de sépalas (CS) e pétalas (CP); comprimento dos filamentos da corona (CFC); comprimento do androginóforo (CA); comprimento da câmara nectarífera, à superfície das anteras (CNSA); comprimento da câmara nectarífera, à superfície do estigma (CNSE), conforme (Brasil, 
2008). A curvatura do estilete (CE) foi descrita conforme Akamine \& Girolami (1959) (Figura 1). Os dados da morfometria floral foram submetidos à análise de variância, e as médias comparadas pelo teste de Tukey, a 5\% de probabilidade, pelo programa estatístico Sisvar (Ferreira, 2011).

Para a avaliação da longevidade floral, as observações foram realizadas de 11:30 às 18:00 h, com intervalos de trinta minutos. Contaram-se os números de flores abertas $(\mathrm{N}=193)$ e flores senescentes $(\mathrm{N}=14)$ de cinco plantas por cultivar. O início do período de senescência caracterizou-se pelo murchamento e pela perda do brilho da corola (que se torna opaca nesta fase). O percentual de flores em antese e senescentes por cultivar foi obtido a partir do número de flores por hora de avaliação, dividido pelo número total de flores e multiplicado por 100. As observações da frequência de visitantes florais foram realizadas das 12:00 às 18:00 h, com intervalos de uma hora, durante sete dias consecutivos, o que totalizou 15 horas de observação. Inicialmente, contou-se o número de flores abertas por cultivar. Posteriormente, realizou-se, nas cultivares e
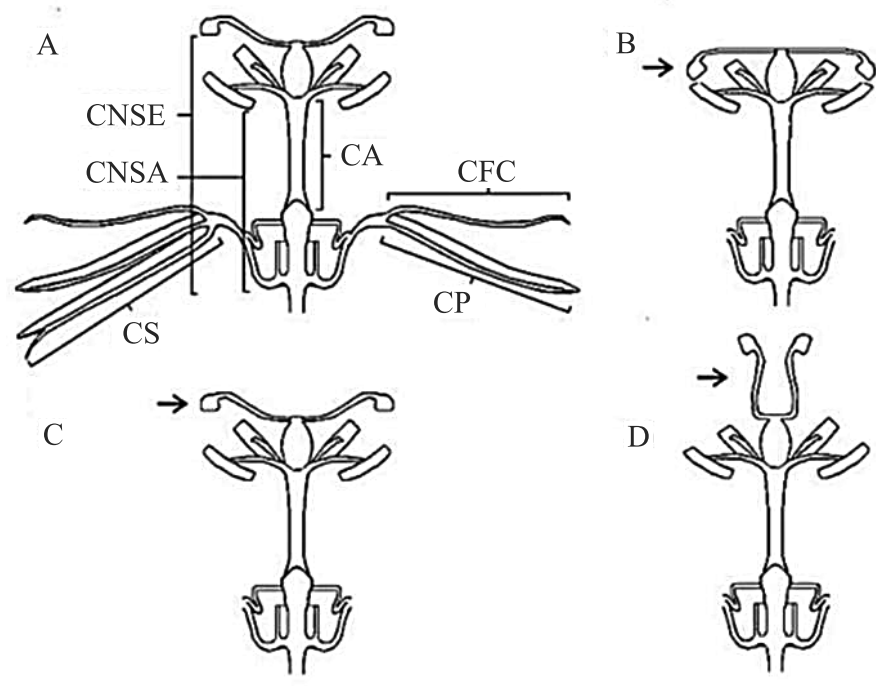

Figura 1. Representação da flor de Passiflora edulis Sims. A, morfometria floral: CS, comprimento da sépala; CP, comprimento da pétala; $\mathrm{CFC}$, comprimento do filamento da corona; CA, comprimento do androginóforo; CNSA, comprimento do nectário à superfície das anteras; CNSE, comprimento do nectário à superfície do estigma. Curvatura do estilete, conforme Akamine \& Girolami (1959): B, estilete totalmente curvo (seta); C, estilete parcialmente curvo (seta); e D, estilete sem curvatura (seta). nas flores inspecionadas, a contagem do número dos visitantes e a frequência de visitação, a cada intervalo de observação. A frequência de visitantes a cada cultivar foi obtida com a soma do número de visitantes por espécie, dividido pelo número total de visitantes e multiplicado por 100. Visitantes florais foram coletados, montados com alfinetes entomológicos e, posteriormente, identificados com o auxílio de especialistas, conforme Silveira et al. (2002).

$\mathrm{O}$ índice de frutificação natural foi avaliado em delineamento inteiramente casualizado, com quatro repetições e cinco flores por cultivar. As flores foram previamente marcadas e acompanhadas até o desenvolvimento inicial dos frutos. A qualidade dos frutos foi avaliada em frutos maduros, em um delineamento inteiramente casualizado, com quatro repetições e cinco frutos por cultivar, por meio das seguintes características físico-químicas: massa de frutos (MF), massa unitária de frutos em gramas, obtida por balança digital; comprimento dos frutos (CF), obtido da dimensão longitudinal; diâmetro médio de frutos (DF), obtido da dimensão equatorial; e espessura média de casca (EC), determinada com a medida de quatro pontos da casca externa, na porção mediana dos frutos (cortados transversalmente, no sentido de maior diâmetro). Para realizar as medidas $\mathrm{MF}, \mathrm{CF}, \mathrm{DF}, \mathrm{EC}$, utilizou-se um paquímetro digital. A percentagem de polpa (PP) foi obtida pela pesagem da polpa (sementes com arilo) em balança digital, cujo valor foi dividido pela massa total do fruto e multiplicado por 100 . O teor de sólidos solúveis totais (SST) foi obtido de alíquotas de suco da polpa, por meio de refratômetro digital portátil, modelo RTD 45 (Instrutherm, SP, Brasil), com leitura na faixa de 0 a $32^{\circ}$ Brix. $\mathrm{O} p H$ da polpa foi obtido por meio de medidor digital de $\mathrm{pH}$, modelo PA200 (Marconi, Piracicaba, SP, Brasil).

O índice de frutificação e as características obtidas da qualidade dos frutos foram submetidas à análise de variância, e as médias foram comparadas pelo teste de Tukey, a 5\% de probabilidade, por meio do programa estatístico Genes (Cruz, 2013).

\section{Resultados e Discussão}

As flores das cultivares de maracujazeiro-azedo apresentaram, quanto à morfologia, sépalas de coloração verde na face abaxial e branca na face adaxial, bem como pétalas completamente brancas 
(Figura 1). As flores apresentaram duas séries de corona bem desenvolvidas, com coloração branca nas extremidades e violeta na base.

As flores das cultivares analisadas apresentaram: androginóforo colunar verde; opérculo inserido na base do androginóforo a delimitar a câmara nectarífera; androceu formado por cinco estames com as anteras dorsifixas, com deiscência longitudinal e móveis; gineceu formado por um ovário globoso, multiovular e com estigma tripartido. Segundo Siqueira et al. (2009), estas características morfológicas permitem que as estruturas reprodutivas se acoplem precisamente à região dorsal do corpo do polinizador, principalmente abelhas de grande porte.

A corona tem o papel de atrair os polinizadores. No maracujazeiro-azedo, a corona possui longos filamentos, e a cor púrpura contrasta com as demais partes florais, que funcionam como uma plataforma de pouso e um atrativo visual; estas características estão associadas a flores polinizadas por insetos como as mamangavas (Xylocopa spp.) (Varassin et al., 2001).

A morfometria floral não apresentou diferença significativa quanto ao comprimento das pétalas, filamentos da corona, androginóforo e curvatura do estilete, o que mostra não haver variabilidade genética quanto a estas características, entre as cultivares avaliadas. Houve diferença significativa de comprimento de sépala, altura da câmara nectarífera à superfície das anteras e altura da câmara nectarífera à superfície do estigma, entre as cultivares avaliadas (Tabela 1).
A percentagem média de $92,5 \%$ de estiletes totalmente curvos, para as cultivares do presente estudo, foi superior às verificadas por Hoffmann et al. (2000), que observaram $76,86 \%$ de flores com estilete totalmente curvo em P. edulis, e Siqueira et al. (2009), que verificaram percentagem média de 70 e $62 \%$ de estiletes totalmente curvos. A proximidade de anteras e estigmas à câmera nectarífera, tal como observado nas cultivares IAC-275-Maravilha, IAC-277-Jóia, BRS SC1 e BRS GA1, facilita o contato das abelhas com as estruturas reprodutivas, no momento da coleta de néctar. Para essas cultivares, a proximidade do nectário às anteras, aliado à máxima curvatura dos estiletes, amplia a possibilidade de uma polinização bem sucedida pelos diferentes grupos de visitantes florais, inclusive abelhas de médio porte. Faleiro et al. (2011) observaram que, em alguns acessos de maracujazeiro-azedo e $P$. odontophylla, no momento de máxima curvatura do estilete, os estigmas chegam a tocar na corona, e isto pode contribuir para a polinização por abelhas menores.

O pico de floração ocorreu às $15: 30 \mathrm{~h}$, quando as oito cultivares apresentavam $100 \%$ de flores abertas. Nas cultivares IAC-275-Maravilha, FB 200 Yellow Master e BRS SC1, o início da antese floral ocorreu mais tardiamente, em comparação com as demais cultivares (Tabela 2). A senescência floral iniciou-se às 17:30 h, do mesmo dia do pico de floração, em $75 \%$ da cultivares analisadas. A cultivar BRS OV1 apresentou a maior longevidade floral (Tabela 3). Em estudos realizados por Benevides et al. (2009), também com

Tabela 1. Morfometria floral de cultivares de Passiflora edulis, em 2013, em Tangará da Serra, MT. ${ }^{(1)}$

\begin{tabular}{|c|c|c|c|c|c|c|c|}
\hline Cultivar & CS & $\mathrm{CP}$ & $\mathrm{CFC}$ & $\mathrm{CA}$ & CNSA & CNSE & $\begin{array}{l}\mathrm{CE} \\
(\%) \\
\end{array}$ \\
\hline 'IAC-277-Jóia' & $33,3 \mathrm{ab}$ & $36,0 \mathrm{a}$ & $27,6 \mathrm{a}$ & $8,3 \mathrm{a}$ & $13,2 \mathrm{~b}$ & $15,1 \mathrm{a}$ & $100,0 \mathrm{a}$ \\
\hline 'IAC-275-Maravilha' & $32,7 \mathrm{abc}$ & $36,3 \mathrm{a}$ & $28,1 \mathrm{a}$ & $8,1 \mathrm{a}$ & $13,0 \mathrm{~b}$ & $15,0 \mathrm{a}$ & $90,0 \mathrm{a}$ \\
\hline 'FB 200 Yellow Master' & $32,7 \mathrm{abc}$ & $36,0 \mathrm{a}$ & $27,5 \mathrm{a}$ & $8,1 \mathrm{a}$ & $13,2 b$ & $18,8 b$ & $100,0 \mathrm{a}$ \\
\hline 'FB 300 Araguari' & $33,1 \mathrm{abc}$ & $35,7 \mathrm{a}$ & $28,1 \mathrm{a}$ & $8,0 \mathrm{a}$ & $14,5 \mathrm{a}$ & $18,5 b$ & $90,0 \mathrm{a}$ \\
\hline 'BRS SC1' & $32,0 \mathrm{a}$ & $36,8 \mathrm{a}$ & $27,6 \mathrm{a}$ & $8,3 \mathrm{a}$ & $13,2 b$ & $15,2 \mathrm{a}$ & $80,0 \mathrm{a}$ \\
\hline 'BRS GA1' & $32,6 \mathrm{bc}$ & $36,4 \mathrm{a}$ & $26,7 \mathrm{a}$ & $8,3 \mathrm{a}$ & $13,2 b$ & $14,8 \mathrm{a}$ & $90,0 \mathrm{a}$ \\
\hline 'BRS RC' & $33,9 \mathrm{c}$ & $36,6 a$ & $28,1 \mathrm{a}$ & $8,4 \mathrm{a}$ & $13,2 b$ & $14,9 \mathrm{a}$ & $100,0 \mathrm{a}$ \\
\hline 'BRS OV1' & $33,1 \mathrm{abc}$ & $36,4 \mathrm{a}$ & $28,1 \mathrm{a}$ & $8,2 \mathrm{a}$ & $13,4 \mathrm{~b}$ & $18,7 \mathrm{~b}$ & $90,0 \mathrm{a}$ \\
\hline Quadrado médio & $3,0^{\mathrm{ns}}$ & $1,2^{\text {ns }}$ & $2,2^{\text {ns }}$ & $0,1^{\mathrm{ns}}$ & $2,4 * *$ & $35,1 * *$ & $500^{\text {ns }}$ \\
\hline $\mathrm{CV}(\%)$ & 2,6 & 36,3 & 4,4 & 5,3 & 4,7 & 6,0 & 29,0 \\
\hline
\end{tabular}

${ }^{(1)}$ Médias seguidas por letras iguais, nas colunas, não diferem entre si, pelo teste de Tukey, a $5 \%$ de probabilidade. **Significativo a $1 \%$ de probabilidade, pelo teste F. CS, comprimento de sépala; CP, comprimento de pétala; CFC, comprimento dos filamentos da corona; CA, comprimento do androginóforo; CNSA, comprimento do nectário à superfície das anteras; $\mathrm{CNSE}$, comprimento do nectário à superfície do estigma; $\mathrm{CE}$, curvatura do estilete. ${ }^{\text {ns Não }}$ significativo. 
o maracujazeiro-azedo, no Rio de Janeiro, os autores constataram que o período de antese iniciou-se às 12:00 h e se estendeu até às 16:30 h. Montero et al. (2013) verificaram que, no Estado de São Paulo, a antese do maracujazeiro-azedo se iniciou às 13:00 h, e a senescência, ao final da tarde.

Quando se considera a percentagem de flores abertas e o número de cultivares na área de estudo, a antese tardia, tal como observado na 'IAC-275-Maravilha', pode comprometer o sucesso reprodutivo pelo compartilhamento de polinizadores. Os baixos índices de senescência floral até as 18:00 h (período máximo de observação) são indicativos de que pode haver atuação de visitantes noturnos, conforme observado em outras espécies de Passiflora, como P. capsularis e P. pohlii (Faria \& Stehmann, 2010).

Durante a antese, os visitantes identificados nas flores do maracujazeiro-azedo foram: Xylocopa frontalis, Bombus sp.1, Bombus sp.2, Trigona chanchamayoensis, Trigona hyalinata e Apis mellifera. As cultivares FB 200 Yellow Master e BRS OV1 receberam o maior número de visitas (Tabela 4).

A abelha $X$. frontalis e as espécies de Bombus se aproximavam de flores onde não havia nenhum outro visitante, pousavam sobre a corona e coletavam o néctar disponível, tocavam as estruturas reprodutivas das flores e transferiam o pólen. A maior atividade dessas abelhas ocorreu entre 13:00 e 15:30 h. A cultivar BRS GA1 recebeu o maior número de visitas dessas abelhas ( $\mathrm{N}=7$ visitas). As espécies T. chanchamayoensis e $T$. hyalinata coletavam néctar pousadas sobre a corona da flor e não foram observadas a tocar as estruturas reprodutivas. O período de maior atividade das trigonas ocorreu entre 14:30 e 16:30 h. A espécie Apis mellifera foi observada a coletar pólen, tendo chegado a retirá-lo completamente das anteras.
Após a retirada do pólen, esta espécie foi observada a coletar o néctar das flores. A. mellifera afugentava abelhas $X$. frontalis e Bombus, se estas tentassem uma aproximação ou até mesmo se já estivessem em visita às flores do maracujazeiro-azedo. $\mathrm{O}$ comportamento de A. mellifera de expulsar os demais visitantes florais também foi observado por Gross \& Mackay (1998). Esta espécie esteve presente durante todo o período de avaliação e visitou todas as cultivares. Alguns autores têm relacionado a presença da $A$. mellifera à redução da disponibilidade de pólen e de atividade das abelhas de grande porte (Siqueira et al., 2009).

Abelhas de grande porte, como as dos gêneros Xylocopa e Bombus, encontradas no presente estudo, são consideradas como polinizadores efetivos do maracujazeiro-azedo (Yamamoto et al., 2010). A baixa frequência das visitas realizadas por estas abelhas na área pode estar relacionada ao uso de defensivos agrícolas e à degradação ambiental. Pinheiro \& Freitas (2010) relataram os efeitos letais de pesticidas agrícolas, de uso autorizado, sobre abelhas polinizadoras em agroecossistemas brasileiros; estes autores mostram o impacto do uso de pesticidas sobre a quantidade de polinizadores em áreas agrícolas e a baixa produtividade em várias culturas. A hora de pico de atividade das abelhas $X$. frontalis, Bombus sp.1 e Bombus sp.2, observadas no presente trabalho, confirmam as observações realizadas por Varassin et al. (2012). A presença destas abelhas na cultura do maracujazeiro pode ser influenciada por diversos fatores, como a produção de néctar, a quantidade de flores disponíveis e a temperatura do ambiente (Silva et al., 2013).

O índice de frutificação natural foi significativamente diferente entre as cultivares avaliadas e variou de 22,5 a 36,7\%; 'BRS SC1' e 'BRS RC' apresentaram os maiores valores para este índice, ambas com $36,7 \%$

Tabela 2. Percentagem de flores abertas, em diferentes horários de avaliação, em oito cultivares de maracujazeiro-azedo, em 2013, em Tangará da Serra, MT.

\begin{tabular}{|c|c|c|c|c|c|c|c|c|c|}
\hline \multirow[t]{2}{*}{ Cultivar } & \multicolumn{9}{|c|}{ Horário de avaliação } \\
\hline & $11: 30$ & $12: 00$ & $12: 30$ & $13: 00$ & $13: 30$ & $14: 00$ & $14: 30$ & $15: 00$ & $15: 30$ \\
\hline 'IAC-277-Jóia' & 22,8 & 42,8 & 77,1 & 91,4 & 97,1 & 100,0 & 100,0 & 100,0 & 100,0 \\
\hline 'IAC-275-Maravilha' & 0,0 & 0,0 & 0,0 & 38,4 & 53,8 & 76,9 & 76,9 & 92,3 & 100,0 \\
\hline 'FB 200 Yellow Master' & 0,0 & 0,0 & 25,0 & 66,6 & 66,6 & 66,6 & 83,3 & 91,6 & 100,0 \\
\hline 'FB 300 Araguari' & 0,0 & 15,7 & 36,8 & 47,3 & 73,6 & 73,6 & 89,4 & 94,7 & 100,0 \\
\hline 'BRS SC1' & 0,0 & 0,0 & 36,3 & 59,1 & 72,7 & 90,9 & 100,0 & 100,0 & 100,0 \\
\hline 'BRS GA1' & 12,9 & 45,1 & 67,7 & 77,4 & 90,3 & 90,3 & 100,0 & 100,0 & 100,0 \\
\hline 'BRS RC' & 16,6 & 46,6 & 66,6 & 80,0 & 86,6 & 86,6 & 100,0 & 100,0 & 100,0 \\
\hline 'BRS OV1' & 19,3 & 54,8 & 77,4 & 87,0 & 100,0 & 100,0 & 100,0 & 100,0 & 100,0 \\
\hline
\end{tabular}


(Tabela 5). O índice de frutificação observado no presente estudo foi baixo, em comparação com os resultados obtidos por Malerbo-Souza et al. (2002), em que a polinização natural foi responsável por uma produção de até 53,85\% no Estado de São Paulo. Baixos índices de vingamento de frutos podem estar relacionados às condições ambientais, fatores edáficos, estado nutricional das plantas (Borges et al., 2006) ou populações insuficientes de mamangavas para suprir a necessidade de polinização, conforme observado no presente estudo. A conservação de áreas de vegetação natural e serviços de polinização têm sido considerados necessários, principalmente para espécies autoincompatíveis, que necessitam da polinização de abelhas de grande porte, como as do gênero Xylocopa, para a produção de frutos. Práticas agrícolas com menor intensidade da ação antrópica são fatores que favorecem a diversidade e a abundância de polinizadores (Ghazoul, 2005; Aizen et al., 2008).

Tabela 3. Percentagem de flores senescentes de oito cultivares de maracujazeiro-azedo, em diferentes horários de avaliação, em 2013, em Tangará da Serra, MT.

\begin{tabular}{lccc}
\hline Cultivar & \multicolumn{3}{c}{ Horário de avaliação } \\
\cline { 2 - 4 } & $17: 00$ & $17: 30$ & $18: 00$ \\
\hline 'IAC-277-Jóia' & 0,0 & 8,5 & 22,8 \\
'IAC-275-Maravilha' & 0,0 & 7,6 & 15,3 \\
'FB 200 Yellow Master' & 0,0 & 0,0 & 16,6 \\
'FB 300 Araguari' & 0,0 & 5,2 & 21,0 \\
'BRS SC1' & 0,0 & 4,5 & 22,7 \\
'BRS GA1' & 0,0 & 9,7 & 19,3 \\
'BRS RC' & 0,0 & 13,3 & 23,3 \\
'BRS OV1' & 0,0 & 0,0 & 6,4 \\
\hline
\end{tabular}

Os frutos produzidos a partir de polinização natural apresentaram valores médios de massa (159,6 g), comprimento $(93,0 \mathrm{~mm})$, diâmetro $(82,6 \mathrm{~mm})$, espessura de casca $(8,3 \mathrm{~mm})$ e percentagem de polpa $(59,2 \%)$. Estes valores foram superiores às médias obtidas por Santos et al. (2009), para as características comprimento de fruto $(86,4 \mathrm{~mm})$ e diâmetro de fruto $(75,9 \mathrm{~mm})$ em Minas Gerais. No estudo realizado no Acre por Negreiros et al. (2008), a média das características comprimento $(73,3 \mathrm{~mm})$ e diâmetro do fruto $(69,3 \mathrm{~mm})$ e espessura de casca $(6,4 \mathrm{~mm})$ foram abaixo das médias encontradas no presente trabalho. Krause et al. (2012b) também obtiveram média de percentagem de polpa $(36,6 \%)$ abaixo da apresentada no presente estudo.

A IAC-275-Maravilha apresentou frutos maiores do que os das demais cultivares, quanto às características massa (192,6 g), comprimento $(103,1 \mathrm{~mm})$ e diâmetro de fruto $(96,3 \mathrm{~mm})$. A espessura da casca foi menor, em média, nas cultivares BRS RC e FB 200 Yellow Master e maior na BRS OV1 (Tabela 5). Frutos de tamanhos maiores são desejáveis para atender principalmente ao mercado in natura. A característica casca fina de frutos atende a uma exigência das indústrias de beneficiamento de frutos, enquanto a casca mais espessa confere aos frutos maior resistência ao transporte e à perda de qualidade, durante o armazenamento e a comercialização (Abreu et al., 2009).

Houve diferença significativa entre as cultivares quanto ao teor de sólidos solúveis totais, que variou de 11,5 a 13,9 ${ }^{\circ}$ Brix (Tabela 5). Os valores obtidos para esta característica, no presente estudo, foram inferiores aos valores médios de $14,6{ }^{\circ}$ Brix, encontrados

Tabela 4. Número de visitantes e percentagem de visitação por abelhas, em oito cultivares de maracujazeiro-azedo, em 2013, em Tangará da Serra, MT.

\begin{tabular}{lcccccc}
\hline Cultivar & \multicolumn{5}{c}{ Número de visitas (percentagem de visitação) } \\
\cline { 2 - 5 } & Xylocopa frontal & Bombus sp. 1 & Bombus sp. 2 & Trigona chanchanoeinsis & Trigona hyalinata & Apis mellifera \\
de visitas
\end{tabular}

Os números entre parênteses referem-se à percentagem de visitação. 
Tabela 5. Características físico-químicas de frutos oriundos de polinização natural, em oito cultivares de maracujazeiro-azedo, em 2013, em Tangará da Serra, $\mathrm{MT}^{(1)}$.

\begin{tabular}{lllllllll}
\hline Cultivar & IF $(\%)$ & MF $(\mathrm{g})$ & CF $(\mathrm{mm})$ & DF $(\mathrm{mm})$ & EC $(\mathrm{mm})$ & PP $(\%)$ & SST $\left({ }^{\circ} \mathrm{Brix}\right)$ \\
\hline 'IAC-277-Jóia' & $24,2 \mathrm{ab}$ & $192,6 \mathrm{a}$ & $103,1 \mathrm{a}$ & $96,3 \mathrm{a}$ & $9,7 \mathrm{bc}$ & $40,1 \mathrm{~b}$ & $11,5 \mathrm{~b}$ & $2,8 \mathrm{ab}$ \\
'IAC-275-Maravilha' & $29,2 \mathrm{~b}$ & $158,8 \mathrm{ab}$ & $95,5 \mathrm{abc}$ & $85,3 \mathrm{abc}$ & $7,3 \mathrm{ab}$ & $65,9 \mathrm{a}$ & $12,0 \mathrm{ab}$ & $2,9 \mathrm{a}$ \\
'FB 200 Yellow Master' & $22,5 \mathrm{~b}$ & $131,8 \mathrm{ab}$ & $85,0 \mathrm{c}$ & $78,4 \mathrm{bc}$ & $6,8 \mathrm{a}$ & $75,2 \mathrm{a}$ & $12,7 \mathrm{ab}$ & $2,8 \mathrm{ab}$ \\
'FB 300 Araguari' & $25,0 \mathrm{~b}$ & $126,4 \mathrm{c}$ & $92,0 \mathrm{abc}$ & $85,9 \mathrm{abc}$ & $7,5 \mathrm{ab}$ & $73,6 \mathrm{a}$ & $13,1 \mathrm{ab}$ & $2,6 \mathrm{~b}$ \\
'BRS SC1' & $36,7 \mathrm{a}$ & $191,7 \mathrm{ab}$ & $92,4 \mathrm{abc}$ & $79,0 \mathrm{bc}$ & $7,7 \mathrm{ab}$ & $51,9 \mathrm{~b}$ & $13,4 \mathrm{ab}$ & $2,9 \mathrm{a}$ \\
'BRS GA1' & $29,2 \mathrm{a}$ & $172,6 \mathrm{ab}$ & $99,3 \mathrm{ab}$ & $88,3 \mathrm{ab}$ & $6,7 \mathrm{a}$ & $60,7 \mathrm{a}$ & $13,5 \mathrm{ab}$ & $2,9 \mathrm{a}$ \\
'BRS RC' & $36,7 \mathrm{a}$ & $145,2 \mathrm{ab}$ & $86,7 \mathrm{c}$ & $73,5 \mathrm{c}$ & $8,7 \mathrm{ab}$ & $56,8 \mathrm{~b}$ & $13,8 \mathrm{a}$ & $3,0 \mathrm{a}$ \\
'BRS OV1' & $33,3 \mathrm{ab}$ & $157,3 \mathrm{ab}$ & $89,8 \mathrm{bc}$ & $73,7 \mathrm{c}$ & $12,2 \mathrm{c}$ & $49,8 \mathrm{~b}$ & $13,9 \mathrm{a}$ & $3,1 \mathrm{a}$ \\
\hline Quadrado médio & $15,5^{* *}$ & $2498,9^{*}$ & $150,4^{* *}$ & $246,2^{* *}$ & $13,8 * *$ & $528,2^{* *}$ & $3,1^{*}$ & $0,1^{* *}$ \\
DMS & 11,25 & 65,92 & 11,21 & 13,68 & 2,88 & 28,09 & 2,21 & 0,30 \\
CV (\%) & 17,6 & 17,6 & 5,14 & 7,1 & 14,8 & 13,0 & 7,3 & 4,5 \\
\hline
\end{tabular}

${ }^{(1)}$ Médias seguidas por letras iguais, nas colunas, não diferem entre si, pelo teste de Tukey, a $5 \%$ de probabilidade. **e *, Significativo a 1 e $5 \%$ de probabilidade, respectivamente, pelo teste F. IF, índice de frutificação; MF, massa do fruto; CF, comprimento do fruto; DF, diâmetro do fruto; EC, espessura da casca; $\mathrm{PP}$, percentagem de polpa; SST, sólidos solúveis totais.

por Krause et al. (2012b), que trabalharam com cultivares comerciais em Terra Nova do Norte, MT. Para a mesma região do presente estudo, Krause et al. (2012a) avaliaram cultivares comerciais de maracujazeiro-azedo e obtiveram valores médios de $14{ }^{\circ}$ Brix para frutos oriundos de polinização natural.

Os valores médios de sólidos solúveis totais obtidos para 'IAC-277-Jóia', 'IAC-275-Maravilha' e 'FB 200 Yellow Master' foram inferiores ao valor mínimo (13 ${ }^{\circ}$ Brix) indicado para os frutos destinados ao mercado in natura ou para a indústria. As cultivares FB 300 Araguari, BRS SC1, BRS RC, BRS GA1 e BRS OV1 apresentaram média acima de $13^{\circ}$ Brix.

Os frutos das cultivares analisadas apresentaram valores médios de $\mathrm{pH}$ entre 2,74 e 3,44. Os valores de $\mathrm{pH}$ obtidos no presente estudo (Tabela 5) confirmam os obtidos por Medeiros et al. (2009). Segundo Campos et al. (2013), frutos com $\mathrm{pH}$ da polpa entre 2,5 e 3,5 são mais adequados ao processamento para produção de suco concentrado do que para o consumo na forma de suco in natura. Assim, com base nas características químicas dos frutos, 'FB 300 Araguari', 'BRS SC1', 'BRS GA1', 'BRS RC' e 'BRS OV1' apresentam requisitos que atendem tanto ao consumo in natura quanto à indústria de suco concentrado.

\section{Conclusões}

1. Nas cultivares IAC-275-Maravilha, IAC-277-Jóia, BRS SC1, BRS RC e BRS GA1, a polinização pode ser realizada por abelhas de médio porte, pois apresentam menor distância entre a câmara nectarífera e a superfície do estilete.

2. 'BRS OV1' apresenta a maior longevidade floral entre as cultivares avaliadas em Tangará da Serra, MT.

3. O índice de frutificação natural, nas cultivares avaliadas em Tangará da Serra, MT, é baixo, o que torna necessária a realização da polinização manual para o aumento da produção.

4. Os frutos de polinização natural apresentam características físicas compatíveis com as exigidas pelo mercado consumidor.

5. As cultivares FB 300 Araguari, BRS SC1, BRS GA1, BRS RC e BRS OV1 destacam-se quanto às características químicas analisadas.

\section{Agradecimentos}

À Coordenação de Aperfeiçoamento de Pessoal de Nível Superior (Capes) e à Fundação de Amparo à Pesquisa do Estado de Mato Grosso (Fapemat), por apoio financeiro e concessão de bolsa de estudos.

\section{Referências}

ABREU, S. de P.M.; PEIXOTO, J.R.; JUNQUEIRA, N.T.V.; SOUZA, M.A. de F. Características físico-químicas de cinco genótipos de maracujazeiro-azedo cultivados no Distrito Federal. Revista Brasileira de Fruticultura, v.31, p.487-491, 2009. DOI: 10.1590/S0100-29452009000200024.

AIZEN, M.A.; GARIBALDI, L.A.; CUNNINGHAM, S.A.; KLEIN, A.M. Long-term global trends in crop yield and production reveal no current pollination shortage but increasing pollinator 
dependency. Current Biology, v.18, p.1572-1575, 2008. DOI: 10.1016/j.cub.2008.08.066.

AKAMINE, E.K.; GIROLAMI, D.G. Pollination and fruit set in the yellow passion fruit. Honolulu: University of Hawaii, 1959. 44p. (Technical bulletin, 39).

BENEVIDES, C.R.; GAGLIANONE, M.C.; HOFFMANN, M. Visitantes florais do maracujá-amarelo (Passiflora edulis $\mathrm{f}$. flavicarpa Deg., Passifloraceae) em áreas de cultivo com diferentes proximidades a fragmentos florestais na região Norte Fluminense, RJ. Revista Brasileira de Entomologia, v.53, p.415-421, 2009. DOI: $10.1590 /$ S0085-56262009000300016.

BERNACCI, L.C.; CERVI, A.C.; MILWARD-DE-AZEVEDO, M.A.; NUNES, T.S.; IMIG, D.C.; MEZZONATO, A.C. Lista de espécies da flora do Brasil: Passifloraceae. Rio de Janeiro: Jardim Botânico, 2013. Disponível em: <http://floradobrasil.jbrj.gov.br/ jabot/floradobrasil/FB182>. Acesso em: 23 nov. 2013.

BORGES, A.L.; CALDAS, R.C.; LIMA, A. de A. Doses e fontes de nitrogênio em fertilização no cultivo do maracujá-amarelo. Revista Brasileira de Fruticultura, v.28, p.301-304, 2006. DOI: 10.1590/S0100-29452006000200033.

BRASIL. Ministério da Agricultura, Pecuária e Abastecimento. Instruções para execução dos ensaios de distinguibilidade, homogeneidade e estabilidade de cultivares de maracujá (Passiflora edulis Sims). Diário Oficial [da] República Federativa do Brasil, 18 dez. 2008. Seção 1, p.49-50.

BRASIL. Ministério da Integração Nacional. Secretaria de Infraestrutura Hídrica. Departamento de Projetos Especiais. Maracujá. Brasília: Ministério da Integração Nacional, 2000. 4p. (FrutiSéries. Minas Gerais, 4).

BRUCKNER, C.H.; SILVA, M.M. Florescimento e frutificação. In: BRUCKNER, C.H.; PICANÇO, M.C. (Ed.). Maracujá: tecnologia de produção, pós-colheita, agroindústria, mercado. Porto Alegre: Cinco Continentes, 2001. p.51-68.

CAMPOS, V.B.; FOGAÇA, T. da S.; ALMEIDA, W.L. de; BARBOSA, J.A.; OLIVEIRA, M.R.T. de; GONDIM, S.C.; CAVALCANTE, L.F. Caracterização física e química de frutos de maracujá-amarelo comercializados em Macapá, Amapá. Revista Brasileira de Produtos Agroindustriais, v.15, p.27-33, 2013.

CRUZ, C.D. GENES - a software package for analysis in experimental statistics and quantitative genetics. Acta Scientiarum. Agronomy, v.35, p.271-276, 2013. DOI: 10.4025/ actasciagron.v35i3.21251.

CRUZ, D. de O.; CAMPOS, L.A. de O. Polinização por abelhas em cultivos protegidos. Revista Brasileira de Agrociência, v.15, p.5-10, 2009.

FALEIRO, F.G.; JUNQUEIRA, N.T.V.; BRAGA, M.F.; OLIVEIRA, E.J. de; PEIXOTO, J.R.; COSTA, A.M. Germoplasma e melhoramento genético do maracujazeiro: histórico e perspectivas. Planaltina: Embrapa Cerrados, 2011. 36p. (Embrapa Cerrados. Documentos, 307).

FARIA, F.S.; STEHMANN, J.R. Biologia reprodutiva de Passiflora capsularis L. e P. pohlii Mast. (Decaloba, Passifloraceae). Acta
Botanica Brasilica, v.24, p.262-269, 2010. DOI: 10.1590/ S0102-33062010000100028.

FERREIRA, D.F. Sisvar: a computer statistical analysis system. Ciência e Agrotecnologia, v.35, p.1039-1042, 2011. DOI: 10.1590/S1413-70542011000600001.

GHAZOUL, J. Buzziness as usual? Questioning the global pollination crisis. Trends in Ecology and Evolution, v.20, p.367-373, 2005. DOI: 10.1016/j.tree.2005.04.026.

GROSS, C.L.; MACKAY, D. Honeybees reduce fitness in the pioneer shrub Melastoma affine (Melastomataceae). Biological Conservation, v.86, p.169-178, 1998. DOI: 10.1016/ S0006-3207(98)00010-X.

HARDER, L.D.; JOHNSON, S.D. Adaptive plasticity of floral display size in animal-pollinated plants. Proceedings of the Royal Society B - Biological Sciences, v.272, p.2651-2657, 2005. DOI: 10.1098/rspb.2005.3268.

HOFFMANN, M.; PEREIRA, T.N.S.; MERCADANTE, M.B.; GOMES, A.R. Polinização de Passiflora edulis f. flavicarpa (Passiflorales, Passifloraceae), por abelhas (Hymenoptera, Anthophoridae) em Campos dos Goytacazes, Rio de Janeiro. Iheringia. Série Zoologia, v.89, p.149-152, 2000. DOI: 10.1590/ S0073-47212000000200002.

JUNQUEIRA, N.T.V.; VERAS, M.C.M.; CHAVES, R. da C.; FIALHO, J. de F.; OLIVEIRA, J.A. de; MATOS, A.P. Manejo da floração do maracujazeiro. Planaltina: Embrapa Cerrados, 2001. 3p. (Embrapa Cerrados. Recomendação técnica, 45).

KÖPPEN, W.; GEIGER, R. Klimakarte der Erde. Gotha: Verlag Justus Perthes, 1928. Wall-map $150 \mathrm{~cm} \times 200 \mathrm{~cm}$.

KRAUSE, W.; NEVES, L.G.; VIANA, A.P.; ARAÚJO, C.A.T.; FALEIRO, F.G. Produtividade e qualidade de frutos de cultivares de maracujazeiro-amarelo com ou sem polinização artificial. Pesquisa Agropecuária Brasileira, v.47, p.1737-1742, 2012a. DOI: $10.1590 /$ S0100-204X2012001200009.

KRAUSE, W.; SOUZA, R.S. de; NEVES, L.G.; CARVALHO, M.L. da S.; VIANA, A.P.; FALEIRO, F.G. Ganho de seleção no melhoramento genético intrapopulacional do maracujazeiro-amarelo. Pesquisa Agropecuária Brasileira, v.47, p.51-57, 2012b. DOI: 10.1590/S0100-204X2012000100008.

MALERBO-SOUZA, D.T.; NOGUEIRA-COUTO, R.H.; TOLEDO, V. de A.A. de. Insetos associados às flores de diferentes espécies de maracujá (Passiflora spp.). Acta Scientiarum. Agronomy, v.24, p.1269-1274, 2002. DOI: 10.4025/actasciagron. v24i0.2280.

MARTINS, J.A.; DALLACORT, R.; INOUE, M.H.; SANTI, A.; KOLLING, E.M.; COLETTI, A.J. Probabilidade de precipitação para a microrregião de Tangará da Serra, Estado do Mato Grosso. Pesquisa Agropecuária Tropical, v.40, p.291-296, 2010.

MEDEIROS, S.A.F. de; YAMANISHI, O.K.; PEIXOTO, J.R.; PIRES, M.C.; JUNQUEIRA, N.T.V.; RIBEIRO, J.G.B.L. Caracterização físico-química de progênies de maracujá-roxo e maracujá-azedo cultivados no Distrito Federal. Revista Brasileira de Fruticultura, v.31, p.492-499, 2009. DOI: 10.1590/ S0100-29452009000200025. 
MONTERO, D.A.V.; MELETTI, L.M.M.; MARQUES, M.O.M. Flowering behaviour of five species of Passiflora cultivated at greenhouse in Southeast Brazil. International Journal of AgriScience, v.3, p.176-181, 2013.

NEGREIROS, J.R. da S.; ARAÚJO NETO, S.E. de; ÁlVARES, V. de S.; LIMA, V.A. de; OLIVEIRA, T.K. de. Caracterização de frutos de progênies de meios-irmãos de maracujazeiro-amarelo em Rio Branco - Acre. Revista Brasileira de Fruticultura, v.30, p.431-437, 2008. DOI: 10.1590/S0100-29452008000200028.

PINHEIRO, J.N.; FREITAS, B.F. Efeitos letais dos pesticidas agrícolas sobre polinizadores e perspectivas de manejo para os agroecossistemas brasileiros. Oecologia Australis, v.14, p.266-281, 2010. DOI: 10.4257/oeco.2010.1401.16.

RUGGIERO, C. Estudos sobre floração e polinização do maracujá amarelo (Passiflora edulis f. flavicarpa Deg.). 1973. 92p. Tese (Doutorado) - Faculdade de Medicina Veterinária e Agronomia de Jaboticabal, Jaboticabal.

SANTOS, C.E.M. dos; BRUCKNER, C.H.; CRUZ, C.D.; SIQUEIRA, D.L. de; PIMENTEL, L.D. Características físicas do maracujá-azedo em função do genótipo e massa do fruto. Revista Brasileira de Fruticultura, v.31, p.1102-1110, 2009. DOI: 10.1590/S0100-29452009000400025.

SILVA, K.N. da; DUTRA, J.C.S.; NUCCI, M.; POLATTO, L.P. Influência dos fatores ambientais e da quantidade de néctar na atividade de forrageio de abelhas em flores de Adenocalymma bracteatum (Cham.) DC. (Bignoniaceae). Entomobrasilis, v.6, p.193-201, 2013. DOI: 10.12741/ebrasilis.v6i3.295.
SILVEIRA, F.A.; MELO, G.A.R.; ALMEIDA, E.A.B. Abelhas brasileiras: sistemática e identificação. Belo Horizonte: Fundação Araucária, 2002. 253p.

SIQUEIRA, K.M.M. de; KIILL, L.H.P.; MARTINS, C.F.; LEMOS, I.B.; MONTEIRO, S.P.; FEITOZA, E. de A. Ecologia da polinização do maracujá-amarelo, na região do Vale do Submédio São Francisco. Revista Brasileira de Fruticultura, v.31, p.1-12, 2009. DOI: 10.1590/S0100-29452009000100003.

VARASSIN, I.G.; TRIGO, J.R.; SAZIMA, M. The role of nectar production, flower pigments and odour in the pollination of four species of Passiflora (Passifloraceae) in south-eastern Brazil. Botanical Journal of the Linnean Society, v.136, p.139-152, 2001. DOI: 10.1111/j.1095-8339.2001.tb00563.x.

VARASSIN, I.G.; XIMENES, B.M.S.; MOREIRA, P.A.; ZANON, M.M.F.; ELBL, P.; LÖWENBERG-NETO, P.; MELO, G.A.R. Produção de néctar e visitas por abelhas em duas espécies cultivadas de Passiflora L. (Passifloraceae). Acta Botanica Brasilica, v.26, p.251-255, 2012. DOI: 10.1590/ S0102-33062012000100024.

VIEIRA, P.F. da S.P.; CRUZ, D. de O.; GOMES, M.F.M.; CAMPOS, L.A. de O.; LIMA, J.E. de. Valor econômico da polinização por abelhas mamangavas no cultivo do maracujá-amarelo. Revista de la Red Iberoamericana de Economía Ecológica, v.15, p.43-53, 2010.

YAMAMOTO, M.; BARBOSA, A.A.A.; OLIVEIRA, P.E.A.M. de. A polinização em cultivos agrícolas e a conservação das áreas naturais: o caso do maracujá-amarelo (Passiflora edulis $\mathrm{f}$. flavicarpa Deneger). Oecologia Australis, v.14, p.174-192, 2010. DOI: $10.4257 /$ oeco.2010.1401.10.

Recebido em 4 de julho de 2014 e aprovado em 2 de dezembro de 2014 